\title{
Jovens estudantes do ensino médio integrado: relações de gênero na formação profissional
}

\begin{abstract}
Resumo:
O presente artigo tem por objetivo identificar as percepções de jovens estudantes do ensino médio integrado sobre o itinerário formativo profissionalizante e da base comum, bem como suas expectativas para depois desta etapa da educação básica, considerando as diferenças e desigualdades de gênero produzidas na escola. O estudo de caráter quantitativo contou com a aplicação de um survey com questões abertas e fechadas junto a 191 estudantes dos cursos de automação industrial e informática do 1, 2 e 3o anos de uma escola da rede pública federal. Os resultados evidenciam diferenças de gênero em relação às preferências entre o itinerário formativo profissional e da base comum, nas atividades em laboratórios e nas expectativas de futuro desses(as) jovens. Para os meninos, há maior preferência pelas disciplinas profissionalizantes combinada com o interesse por carreiras correlatas como engenharias e informática. As meninas, por outro lado, valorizam mais as disciplinas da base comum, indicam uma variedade maior de profissões.
\end{abstract}

\section{Palavras-chave:}

Juventude. Educação profissional. Gênero. Projetos de futuro.

\section{Young of integrated high school: educational pathways, projects for the future and gender inequalities}

\begin{abstract}
The purpose of this article is to identify the perceptions of young students in this teaching modality about the professionalizing and common base training itinerary, as well as their expectations for after this stage of basic education, considering the gender differences and inequalities produced at school. The study of a quantitative nature included the application of a survey with open and closed questions with 191 students of the courses in industrial automation and computer science of the 1st, 2nd and 3rd years of a federal school. The results show gender differences in relation to the preferences between the professional training path and the common base, in the activities in laboratories and in the expectations of the future of these young women. For boys,
\end{abstract}

\footnotetext{
1 Doutorando pelo Programa de Pós-Graduação em Educação (PPGed-So), Universidade Federal de São Carlos campus Sorocaba. E-mail: caique.diogo@outlook.com.br. ORCID iD: http://orcid.org/0000-0002-6610-1299.

2 Doutora em Educação, docente do Programa de Pós-Graduação em Educação (PPGed-So), Universidade Federal de São Carlos campus Sorocaba. E-mail: carla.corrochano@gmail.com. ORCID iD: http://orcid.org/0000-0001-8030-6461.
} 
there is a greater preference for professional disciplines combined with interest in related careers such as engineering and computer science. Girls, on the other hand, value the subjects of the common base more and have a larger set of professions.

Keywords: Youth. Professional education. Gender. Future projects.

\section{Jóvenes en la escuela secundaria:itinerarios formativos, proyectos futuros y desigualdades de género}

Resumen: El propósito de este artículo es identificar las percepciones de los jóvenes estudiantes de esta modalidad docente sobre el itinerario formativo profesionalizante y de base común, así como sus expectativas para después de esta etapa de la educación básica, considerando las diferencias y desigualdades de género producidas en la escuela. El estudio de carácter cuantitativo incluyó la aplicación de una encuesta con preguntas abiertas y cerradas a 191 alumnos de los cursos de automatización industrial e informática de 1o, 2 y 3 curso de una escuela federal. Los resultados muestran diferencias de género en relación a las preferencias entre la trayectoria de formación profesional y la base común, en las actividades en los laboratorios y en las expectativas de futuro de estas jóvenes. En el caso de los niños, existe una mayor preferencia por las disciplinas profesionales combinada con el interés en carreras relacionadas como la ingeniería y la informática. Las niñas, en cambio, valoran más los temas de la base común y tienen un conjunto más amplio de profesiones.

Palabras clave: Juventud. Educación professional. Género. Proyectos futuros.

\section{Introdução}

Acompanhando as mudanças na sociedade brasileira, na primeira década dos anos 2000 , as políticas de ampliação da rede federal sinalizaram com novas possibilidades de formação para os(as) jovens brasileiros(as) (FERREIRA; ANDRADE; SOUZA, 2018). Em tempos onde a reforma do ensino médio, sancionada em 2017, objetiva construir itinerários de formação que voltam a fortalecer opção pela educação profissional aos(às) jovens (FERRETI; SILVA, 2017; MOTTA; FRIGOTTO, 2017; RAMOS NETO, 2017; LEÃO, 2018), este estudo irá se debruçar sobre a realidade de jovens do ensino médio integrado com o objetivo de identificar suas percepções acerca dos itinerários formativos desta modalidade de ensino, bem como suas expectativas para depois desta etapa da educação básica, considerando as diferenças e desigualdades de gênero produzidas na escola.

A perspectiva proposta por Antônio Cândido (1978) inspirou esse processo investigativo. O autor defende a necessidade de considerar a escola não somente como resultado da estrutura administrativa e burocratizada, mas também das relações sociais que não estão oficialmente previstas, ou seja, nascem da própria dinâmica do grupo social escolar. Entre essas relações destacaremos as relações de gênero presentes na escola, especialmente aquelas que são produzidas nas salas de aula por meio das disciplinas e/ou nos laboratórios.

A escola investigada está situada na Região Metropolitana de Sorocaba, mais especificamente na cidade de Salto. Trata-se de uma cidade do interior paulista, localizada a $104 \mathrm{~km}$ da capital São Paulo, com uma pequena área territorial quando comparada com seus vizinhos - Itu, Indaiatuba, Sorocaba e Campinas - contudo, essa área territorial é ocupada por um alto grau de urbanização (IBGE, 2019a).

Esta escola é fruto do processo de retomada da expansão da rede federal de educação profissional na primeira década do século XXI (BRASIL, 2017a; BRASIL, 2017b). Dada a baixa cobertura da rede federal - cerca de $2 \%$ das matrículas de ensino médio no Brasil -, para ingressar nessa escola 
os(as) jovens passam por um processo seletivo. Conseguir uma vaga nos cursos de ensino médio integrado na rede federal ainda é um desafio, pois, o número de candidatos inscritos geralmente é maior que o número de vagas ofertadas'.

Os cursos de ensino médio oferecidos na escola - automação industrial e informática contribuíram para o foco dessa investigação, haja vista que são cursos voltados à área de tecnologia. Logo, torna-se relevante investigar as percepções dos(as) estudantes sobre os itinerários formativos disponíveis na escola, bem como as desigualdades produzidas neles e a partir deles considerando as experiências de moças e rapazes estudantes destes cursos.

A investigação foi conduzida a partir de métodos quantitativos. Tendo em vista serem relevantes abordagens dessa natureza como forma de estimular a reflexão e as proposições no campo de estudos sobre jovens (SPOSITO; SOUZA; SILVA, 2018). Para coletar os dados da investigação, recorremos a uma primeira etapa com rodas de conversas com estudantes de uma mesma turma; posteriormente, utilizamos questionários que foram respondidos por 191 adolescentes alunos(as) dos 10, 2o e 3 anos do ensino médio integrado da escola. Além de reiterar a importância de conhecer a multiplicidade presente na categoria juventude, o estudo busca evidenciar algumas desigualdades de gênero presentes no cotidiano da escola.

\section{A pesquisa}

Para investigar os(as) sujeitos(as) da pesquisa recorremos à juventude como uma categoria de investigação. Conforme destacam as pesquisas sobre o conceito, a juventude é uma construção social historicamente situada (LEVI; SCHMITT, 1996; PERALVA, 1997), não se constitui em uma categoria única e homogênea. Seu uso atual, na sociologia da educação brasileira, segundo Sposito e Tarábola (2019, p. 2), deve ir além dos limites demográficos, reconhecendo as desigualdades e as diferenças presentes em seu interior.

Indeed, structural factors derived from social positions, gender relations, and ethnic-racial relations, among others, impose on the researcher the responsibility of remaining attentive and reflective in contacts with the research subjects ${ }^{2}$.

Essas diferenças entre os jovens têm sido explorada pela literatura do campo de estudos da juventude apontando com a necessidade de entender a juventude no plural, isto é, falar sobre juventudes. Nesse sentido, importa indicar que a juventude tem gênero, e discutir a juventude envolve compreender a experiência de mulheres e homens jovens. O gênero enquanto marco de investigação social deriva do debate feminista no sentido de compreender as diferenças percebidas entre os sexos (SCOTT, 1995). Para Connell e Pearse (2016, p. 17), “O gênero, pode-se dizer, é especificamente uma questão de corporificação social na qual as posições sociais são combinadas na construção social e cultural sobre o corpo".

Conforme Welzer-Lang (2004, p. 115) há uma tendência entre os estudos de gênero para dar ênfase às diferenças entre o masculino e o feminino, nesse sentido, o autor afirma que:

Os(as) pesquisadores(as) devem aceitar como postulado que não só as informações sobre as formas da dominação são diferentes como também eles/elas devem extrair delas consequências científicas. Não mais pesquisar a qualquer preço o que faz a diferença entre os sexos, mas descrever e compreender como a diferença é construída socialmente - sobretudo por meio da definição assimétrica dos fatos sociais - para ocultar as relações sociais de sexo.

1 No ano de 2019, o curso de nível médio integrado em automação industrial contou com 5,73 inscritos por vaga, e o integrado em informática contou com 6,53 inscritos por vaga (BRASIL, 2019).

2 Nesse sentido, fatores estruturais derivados de posições sociais, relações de gênero, e as relações étnico-raciais, entre outras, impõem ao pesquisador a responsabilidade de permanecer atento e reflexivo nos contatos com os assuntos de pesquisa (tradução nossa). 
O autor ainda acrescenta que as construções de sentido sobre um objeto seguem duas simbologias diferentes a depender do gênero do(a) observador(a). Enfatizar as diferenças entre moças e rapazes estudantes do ensino médio não significa dizer que são fundamentalmente diferentes, mas, que situações as quais iremos apontar reforçam diferenciações entre homens e mulheres.

Contribuindo para análises quantitativas que serão apresentadas a seguir, Artes e Carvalho (2010) alertam sobre o uso da categoria gênero em pesquisas quantitativas. Segundo as autoras não se pode inferir com indicadores de gênero, mas sim de sexo, haja vista que as pesquisas quantitativas, nesse caso um questionário, se referem ao sexo do(a) respondente e não a seu lugar social, ou seja, a identidade ou o posicionamento nas relações de gênero. Assim como sugerem essas autoras, utilizamos a variável sexo na coleta de resultados e o gênero será utilizado como categoria de análise para ajudar a explicar as diferenças encontradas entre as percepções de rapazes e moças.

A entrada na escola e o encontro com os(as) jovens foi um processo que ocorreu ao longo de oito meses. Os primeiros contatos com a escola ocorreram em busca das condições de viabilidade da primeira e segunda etapas desse estudo, que vieram a ocorrer no mês de outubro de 2017 e abril de 2018. Na primeira etapa, houve uma roda de conversa com estudantes no intuito de realizar uma aproximação inicial e formular as primeiras hipóteses sobre os dilemas que esses(as) jovens vivenciavam na instituição.

Na segunda etapa, o instrumento de pesquisa consistiu de um questionário estruturado, autoaplicável, com questões abertas e fechadas. Questionários possibilitam ao pesquisador coletar dados referentes a uma população maior do que aquela investigada por meio de entrevistas (FREITAS; OLIVEIRA; SACCOL; MOSCAROLA, 2000; PARANHOS; FIGUEIREDO FILHO; ROCHA; SILVA JUNIOR, 2013). A coleta de dados e, posteriormente, a análise contou com o apoio do software computacional QuestionPro. Com ele foi possível gerar um link para acesso on-line para os(as) participantes responderem às questões. Na maior parte dos casos, as turmas eram divididas em duas, facilitando o apoio do pesquisador para eventuais dúvidas com o uso da ferramenta computacional.

Foi ressaltado aos(às) estudantes que a participação era voluntária. Houve casos de alunos(as) que decidiram não participar e preferiram realizar outras atividades durante o tempo que foi disposto para a realização do questionário. Para aqueles que não conseguiram acessar a plataforma ou encontraram problemas de conexão - pouco menos de $8 \%$ dos respondentes -, foi disponibilizado o link de acesso para responder em outra oportunidade.

A coleta de dados não teve como objetivo realizar uma pesquisa censitária, uma vez que contou com a participação voluntária, de modo que podemos classificá-la como uma amostra por conveniência. No entanto, a amostra proporcionou dados significativos para reflexões sobre a população em questão, haja vista que a análise contou com 191 questionários válidos, conferindo uma confiabilidade de $95 \%$ e erro amostral de $4 \%$ considerando uma estimativa da população geral da escola de 240 estudantes.

\section{Breve perfil dos(as) estudantes}

A primeira parte do questionário foi construída com o objetivo de conhecer o perfil dos(as) estudantes. Os(as) participantes da pesquisa são jovens adolescentes do 1, 2ㅇ e 3o anos dos cursos de ensino médio integrado em automação industrial e informática. Verificamos uma certa paridade entre os cursos com base no número de respondentes. Há proximidade entre a quantidade de estudantes respondentes do curso técnico integrado em automação industrial $(48,2 \%)$ e informática (51,8\%). A faixa etária da amostra está situada entre 14 e 18 anos. Nenhum dos(as) participantes da pesquisa assinalou ter interrompido os estudos, e 4 discentes assinalaram ter reprovado alguma série até o momento, representando $2 \%$ dos(as) estudantes da amostra. 
O resultado do questionário aponta que a escola possui mais alunos do sexo masculino $(61,7 \%)$ do que estudantes do sexo feminino (38,3\%). Ao relacionar as diferenças de gênero em relação aos cursos, constata-se uma diferenciação dos cursos entre si com o uso da variável sexo. Essa predominância de estudantes do sexo masculino, corrobora outros estudos empíricos com estudantes do ensino médio da rede federal (ANJOS, 2013; CAÚ, 2017).

Porém, essa disparidade entre os sexos parece não ser percebida por todos(as) os(as) estudantes. Quando perguntados(as) se eles(as) percebem haver desigualdade na entrada de meninos e meninas no ensino médio integrado da escola, $60 \%$ não consideram haver uma desigualdade de gênero em relação ao ingresso na escola; $16,8 \%$ opinaram que ingressam mais meninos, enquanto $7,3 \%$ sentem que ingressam mais meninas e $15,7 \%$ responderam não saber sobre essa questão.

Outro marcador importante referente ao perfil dos(as) estudantes que iremos explorar é a autoidentificação de cor/raça. Com base no método de autodeclaração, comumente utilizado pelo IBGE quando realiza o censo, verificou-se que $60 \%$ dos(as) estudantes se autodeclaram brancos, $30 \%$ pardos, $7 \%$ pretos, $2 \%$ amarelos e aproximadamente $1 \%$ preferiu não declarar.

Tabela 1 - Comparativo entre a autodeclaração de "cor/raça" entre os(as) estudantes da escola e os municípios de Salto que possuem alunos na escola.

\begin{tabular}{cccc}
\hline “Cor/raça” & $\begin{array}{c}\text { Corpo discente } \\
\text { da escola }\end{array}$ & $\begin{array}{c}\text { Municípios que } \\
\text { possuem estu- } \\
\text { dantes na escola }\end{array}$ & $\begin{array}{c}\text { Município } \\
\text { de Salto }\end{array}$ \\
\hline Branco(s) & $60 \%$ & $67 \%$ & $69 \%$ \\
\hline Pardos(s) & $30 \%$ & $25 \%$ & $25 \%$ \\
\hline Preto(s) & $7 \%$ & $6 \%$ & $5 \%$ \\
\hline Amarelo(s) & $2 \%$ & $1 \%$ & $0 \%$ \\
\hline Indígena(s) & $0 \%$ & $1 \%$ & - \\
\hline Sem declaração & $1 \%$ & - & $1 \%$ \\
\hline
\end{tabular}

Fonte: Elaborada pelos autores com base na Seade (2019). Questionário aplicado entre 16/04/2018 e 20/04/2018.

Conforme os dados da Tabela 1, a escola possui uma representatividade de "cor/raça" semelhante à localidade onde está inserida. Vale lembrar que o processo seletivo de ingresso no ensino médio integrado conta com o suporte de políticas de ações afirmativas, como sugerem as diretrizes da Lei no 12.711, de $2012^{4}$. Por mais que a política de cotas possibilite a entrada de estudantes pardos(as) e pretos(as), o número de estudantes do sexo feminino autodeclaradas pretas ainda é baixo em relação ao total de estudantes, menos de $2 \%$ do corpo discente. Ainda que essas ações não garantam que a permanência e a experiência desses(as) jovens na escola ocorram de forma equitativa (SANTOS, 2018).

Em relação à escolaridade dos genitores/responsáveis, verificamos que enquanto os dados da PNAD 2018 (IBGE, 2019b) apontam que 18,3\% das mulheres brasileiras com 25 anos ou mais e 14,5\% dos homens brasileiros com mesma idade possuem graduação em nível superior; entre os genitores/responsáveis dos(as) jovens estudantes percebemos que 28,3\% das mães e 28,8\% dos pais possuem graduação de nível superior. Ou seja, os(as) jovens que conseguem ingressar no ensino médio integrado ao ensino profissionalizante nesta escola da rede federal provêm de famílias com maior escolaridade em relação à média brasileira.

3 Considerando uma média entre os municípios de Salto, Itu, Indaiatuba, Campinas e Cabreúva.

4 A política determina que no mínimo 50\% (cinquenta por cento) das vagas sejam destinadas para estudantes que cursaram integralmente o ensino fundamental em escolas públicas, sendo que dessas vagas, $50 \%$ (cinquenta por cento) deverão ser reservados aos estudantes oriundos de famílias com renda igual ou inferior a 1,5 salário-mínimo (um salário-mínimo e meio) per capita. 


\section{A base comum e o ensino profissionalizante}

O ensino profissionalizante é uma das bases do ensino médio integrado, representando $1 / 3$ da matriz curricular do curso. Ainda que alguns estudantes não queiram seguir a área do curso técnico realizado junto ao médio, alguns deles(as) ressaltam o papel do ensino técnico não como um instrumento para uma inserção no mercado de trabalho, mas como possibilidade de ter acesso a um determinado campo do conhecimento. Durante a roda de conversa uma estudante do primeiro ano disse:

É gratificante para mim estar aqui, porque mesmo não sendo algo que você queira como profissão, de alguma forma a gente que faz informática algo do cotidiano [...] a gente necessita de alguma forma saber um pouco mais, já que a geração está sendo influenciada por isso (Aluna 1, 1o ano de informática).

$\mathrm{Na}$ análise quantitativa percebemos que o corpo discente da escola, de forma geral, apontou uma leve diferença entre preferir as disciplinas profissionalizantes $(43,4 \%)$ e as disciplinas da base comum (38,7\%). Já quando a questão passa a ser estratificada por sexo, verifica-se uma diferença significativa e inversamente proporcional entre a preferência de jovens homens e mulheres, como podemos ver nos gráficos a seguir:

\section{Gráfico 1 - Disciplinas preferidas, segundo a variável sexo}
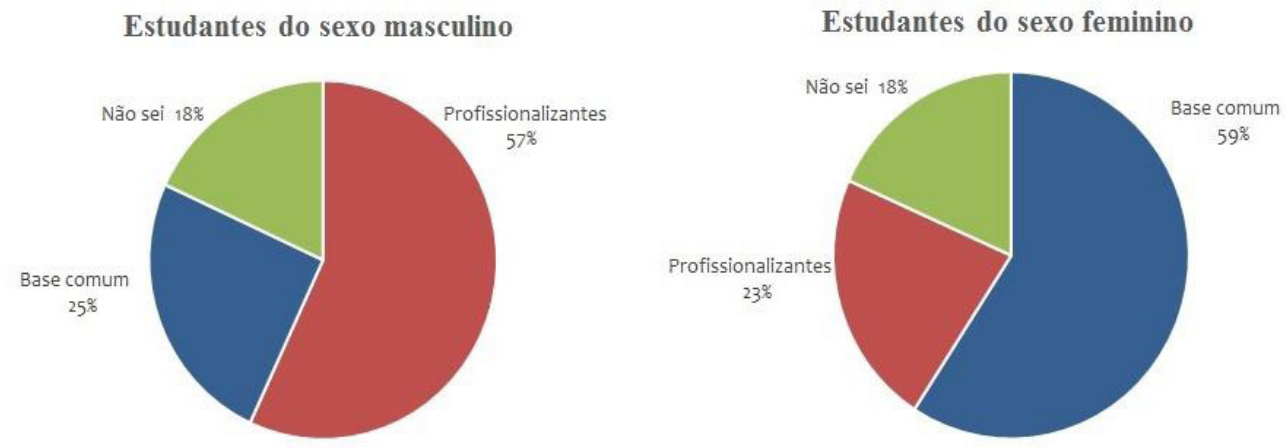

Fonte: Elaborado pelos autores. Questionário aplicado entre 16/04/2018 e 20/04/2018.

Quando a variável sexo é relacionada para abordar a questão, há uma inversão em relação às preferências entre as disciplinas da base comum e as disciplinas profissionalizantes. De um lado, entre os estudantes do sexo masculino, $57 \%$ responderam preferir as disciplinas profissionalizantes, de outro lado, considerando as respostas apenas das estudantes do sexo feminino, $59 \%$ das alunas preferem as disciplinas da base comum.

Essa diferença entre a preferência do público feminino e masculino não significa necessariamente uma atribuição de menor importância à qualificação profissional oferecida pelo curso, pois $85,3 \%$ dos meninos e $85,5 \%$ das meninas consideram a qualificação profissional oferecida pelo curso como muito importante ou totalmente importante na experiência de estudar na instituição federal.

Não pretendemos a partir dos resultados do Gráfico 1 estabelecer uma percepção opositiva e linear, relacionando as meninas à base comum e os meninos às disciplinas profissionalizantes, pois, conforme aponta Connell (2015, p. 47), "Acima de tudo, o gênero é uma questão de relações sociais dentro das quais indivíduos e grupos atuam". Ou seja, o gênero pode ser percebido tendo em vista as ações e percepções dos sujeitos(as) e os grupos em que estão inseridos(as). Em complemento a essa noção da construção social de gênero Carvalho e Tortato (2009, p. 29) afirmam a necessidade de abordar a questão de gênero como construção social, 
[...] desconfiando de dualismos universais que colocam as características de homens e mulheres como fixas, diferentes e muitas vezes opostas, e ainda pretendem universalizar essas características como se as mulheres fossem todas iguais em toda parte do mundo ou até dentro de uma mesma sociedade, criando esses essencialismos universais tanto para elas, como para os homens.

Pretendemos assim, compreender essa diferença na preferência dos alunos pelas disciplinas profissionalizantes e das alunas pelas disciplinas da base comum, como resultado de construções sociais em trânsito. Dessa forma, caracterizaremos alguns pontos presentes na experiência escolar que nos parecem relevantes para entender essa questão: (1) a composição do corpo docente; (2) as desigualdades de gênero nos laboratórios.

A composição do corpo docente da escola possui diferenças entre o grupo que ministra as disciplinas da base comum e o grupo de professores que ministra as disciplinas profissionalizantes. Com base nos PPCs dos dois cursos, identificamos que há mais professoras entre o grupo que ministra a base comum, sendo, para ambos os cursos, 10 do sexo feminino e 7 do sexo masculino. Já entre os grupos de professores das disciplinas profissionalizantes, encontramos uma maioria de professores do sexo masculino, sendo, no curso de informática 6 professores e 1 professora. No curso de automação industrial essa relação é de 10 do sexo masculino para 2 do sexo feminino. Além dos professores, os coordenadores dos dois cursos no momento da pesquisa eram do sexo masculino ${ }^{5}$.

O predomínio de professoras nas disciplinas da base comum e professores nas disciplinas profissionalizantes nos remete a uma reflexão sobre a identificação na relação professor-aluno que essa desigualdade pode trazer. Pois, como afirma Krawczyk (2011, p. 9), "Para os estudantes, o sentido da escola está bastante vinculado à sua integração escolar e à sua identificação com o professor”. Assim, a relação professor-aluno não é mediada apenas pelo saber, mas também, de um lado, por identificação e solidariedade, e de outro por exclusão e violência.

A utilização de artefatos tecnológicos para a construção do conhecimento não é uma novidade, existindo desde as ideias pedagógicas da "escola nova", onde se valorizava a participação ativa dos(as) educandos(as), realizada com foco em atividades de experimento. Todavia, é importante ressaltar o potencial de construção simbólica de gênero presente nesses artefatos, podendo ora desconstruir concepções pré-concebidas sobre o papel do masculino e do feminino, ora reforçar essas concepções (SANTOS; FARIAS, 2009).

Visto que a escola disponibiliza diversos laboratórios para atividades de cunho técnico/ profissionalizante, questionamos os(as) estudantes sobre possíveis desigualdades de gênero percebidas na utilização das ferramentas dos laboratórios. De modo geral, abrangendo os cursos de automação industrial e informática, os resultados apontam que $75,9 \%$ do alunado considera haver uma igualdade de gênero na utilização das ferramentas dos laboratórios, 17,8\% afirmam que os estudantes do sexo masculino utilizam mais essas ferramentas, $0,5 \%$ apontam ser o gênero feminino e $5,8 \%$ não sabem responder a essa questão.

A compreensão dessas respostas exige um olhar mais detalhadamente para os cursos, uma vez que os laboratórios de automação industrial e de informática possuem especificidades que tendem a evidenciar mais ou menos essas desigualdades. Nos laboratórios destinados aos cursos de informática, geralmente, há computadores disponíveis a todos(as), dificultando situações de disputa sobre quem, ou como vai usá-los. Assim, 88,9\% dos(as) estudantes do técnico integrado em informática responderam que há igualdade de gênero na utilização dessas ferramentas do laboratório, $6 \%$ responderam que os meninos utilizam mais esses equipamentos e $1 \%$ respondeu que as meninas utilizam mais, e 5\% não souberam responder.

5 Esses dados corroboram com alguns dos resultados encontrados no estudo feito por Incerti, Carvalho, Casagrande (2017), por meio de fontes documentais do Instituto Federal do Paraná - IFPR -, as autoras identificaram que há uma predominância de professores em disciplinas profissionalizantes, uma leve superioridade quantitativa de professoras nos cursos da base comum. 
No curso integrado em automação industrial, cujos laboratórios ocupam o primeiro andar do prédio, verificamos diferenças significativas em relação às desigualdades de gênero na utilização das ferramentas em comparação ao técnico em informática. Para 63\% dos(as) estudantes, há igualdade entre meninos e meninas na utilização das ferramentas, $30 \%$ apontou que os meninos usam mais as ferramentas nesses espaços. Ninguém respondeu que no curso de automação as meninas utilizam mais ferramentas nos laboratórios e 7\% não soube responder.

Ao comparar a resposta dos dois cursos, verificamos que, enquanto $6 \%$ dos respondentes do curso de informática identificam que os meninos utilizam mais as ferramentas, no curso de automação industrial, essa percepção alcança 30\%. Essa desigualdade maior no curso de automação industrial é reforçada pela predominância de estudantes do sexo masculino em relação ao feminino, conforme relatamos acima no perfil dos cursos. Além disso, as diferenças entre os próprios laboratórios de informática e automação industrial. A escola possui quatro laboratórios de informática, alguns com máquinas o suficiente para todos(as) os(as) estudantes da sala em atividades. Já nos laboratórios de automação industrial, são utilizados tornos de CNC, furadeira de bancada, kits de instrumentos de medição, máquinas de solda entre outros materiais utilizados nos centros de trabalho e de desenvolvimento tecnológico.

Tendo em vista que as atividades geralmente são realizadas em grupos, possivelmente no interior desses grupos há situações em que a utilização dos tornos de CNC coloca meninos e meninas diante da opção de utilizar essas ferramentas; nesse sentido, considerando a predominância de jovens do sexo masculino, propicia-se o ambiente para a reprodução de desigualdades de gênero. Segundo Faulkner (2007) há uma associação entre os homens e o trabalho e habilidades manuais, propiciando um afastamento das mulheres aos estudos no campo tecnológico.

Durante a roda de conversa foi possível ouvir alguns estudantes revelando o quanto o curso condiz com suas expectativas de futuro:

Pra mim está totalmente dentro, bem articulado, as matérias aqui com o que quero, visto que o meu sonho sempre foi trabalhar na área de informática e computação. (Aluno 1, 2o ano de Informática).

O ensino médio ajudou muito, pois, tanto no ensino médio quanto no técnico tem coisas que vão me ajudar na minha futura carreira como a área de matemática ou as áreas técnicas como programação e análise e modelagem de sistemas. (Aluno 2, 2o ano de informática).

Já por outro lado, podemos ouvir jovens relatando que não desejam continuar na área do curso técnico:

O curso que eu faço aqui não me ajuda em nada nessa área, eu acho que ele vai me ajudar em pequenas coisas na minha vida, por exemplo, uma coisa bem boba mesmo, mas, trocar a resistência do chuveiro, ou sei lá, coisas desse tipo sabe. Mas em relação a coisas que eu quero fazer no meu futuro ele não vai me ajudar em nada, porque eu pretendo não seguir essa área, não mesmo. (Aluna 2, 2o ano de Automação industrial).

As disciplinas da base comum possuem valor para a construção dos projetos de futuro. Apenas $1 \%$ dos(as) estudantes - tanto do sexo masculino, quanto do feminino - assinalaram que as disciplinas da base comum não auxiliam na formulação dos projetos de futuro. Há uma maior valorização dessas disciplinas pelo público feminino da escola (75\%) em relação aos meninos (63\%), algo já esperado, uma vez que as alunas majoritariamente preferem as disciplinas da base comum às profissionalizantes. 
Tabela 2 - Auxílio das disciplinas da base comum na elaboração dos projetos de futuro

\begin{tabular}{llll}
\hline \multicolumn{4}{c}{$\begin{array}{c}\text { Cursar as disciplinas da base comum auxilia na elaboração } \\
\text { dos seus projetos de futuro para depois do ensino médio? }\end{array}$} \\
\hline & Geral & Masculino & Feminino \\
\hline Sim & $66 \%$ & $63 \%$ & $75 \%$ \\
\hline Em parte & $23 \%$ & $25 \%$ & $15 \%$ \\
\hline Não & $1 \%$ & $1 \%$ & $1 \%$ \\
\hline Não sei & $10 \%$ & $11 \%$ & $8 \%$ \\
\hline
\end{tabular}

Fonte: Elaborada pelos autores. Questionário aplicado entre 16/04/2018 e 20/04/2018.

Essas percepções indicam um contraste com a Reforma do Ensino Médio proposta na Lei 13.415/2017. Os principais argumentos entre os defensores da reforma referem-se ao fato de que os alunos poderão escolher quais cursos realizar de acordo com seus interesses. Além disso, eles argumentam que os(as) adolescentes ficariam mais motivados a continuar os estudos com a oferta de ensino profissionalizante, que os prepararia para o ingresso no mercado de trabalho (FERRETI; SILVA, 2017; MOTTA; FRIGOTTO, 2017).

Embora os(as) jovens possuam uma rotina composta por muitas disciplinas, por estar em uma escola de ensino de tempo integral, as disciplinas da base comum são relevantes para seus projetos de vida. Mais do que auxiliar no ingresso no mercado de trabalho, as disciplinas da base comum também contribuem para as expectativas de futuro.

Em relação ao auxílio das disciplinas profissionalizantes na elaboração dos projetos de futuro, há uma questão de gênero envolvida na percepção desses(as) estudantes. Para 62\% dos meninos as disciplinas profissionalizantes auxiliam na elaboração dos projetos de futuro e para as alunas esse percentual é de $27 \%$. Na resposta das meninas, percebemos uma dispersão entre "sim" (27\%), "em parte" (38\%), "não" (28\%) e 7\% assinalaram não saber responder. Já entre os meninos, $62 \%$ apontam que "sim", enquanto 5\% responderam que "não", $22 \%$ responderam "em parte" e $11 \%$ dos meninos não souberam responder a essa questão.

Tabela 3 - Auxílio das disciplinas profissionalizantes na elaboração dos projetos de futuro

\begin{tabular}{l|l|l|l}
\hline \multicolumn{4}{c}{$\begin{array}{c}\text { Cursar as disciplinas profissionalizantes auxilia na elaboração } \\
\text { dos seus projetos de futuro para depois do ensino médio? }\end{array}$} \\
\hline & Geral & Masculino & Feminino \\
\hline Sim & $49 \%$ & $62 \%$ & $27 \%$ \\
\hline Em parte & $27 \%$ & $22 \%$ & $38 \%$ \\
\hline Não & $14 \%$ & $5 \%$ & $28 \%$ \\
\hline Não sei & $9 \%$ & $11 \%$ & $7 \%$ \\
\hline Fonte: Elaborada pelos autores. Questionário aplicado entre $16 / 04 / 2018$ e 20/04/2018.
\end{tabular}

Ao pensar a relação entre essas disciplinas e os projetos de futuro, percebemos que essas relações generificadas persistem, pois, os meninos consideram a base técnica como elemento que auxilia na formação dos projetos de futuro para depois do ensino médio em maior quantidade que as meninas.

Essa preferência por itinerários formativos e a relação deles com os projetos de futuro, sugere um questionamento: a preferência do(a) estudante em relação aos itinerários de formação da base comum ou profissionalizante coaduna com expectativas de inserção profissional para áreas correlatas ao curso? Primeiramente, faz-se relevante perguntar sobre as expectativas para depois do ensino médio. Logo, foi possível constatar que a maior parte dos(as) estudantes pretende ingressar no ensino superior. Na questão, os respondentes puderam assinalar mais de uma opção na resposta, o ingresso no ensino superior $(70,7 \%)$ foi a opção mais assinalada entre as repostas corroborando alguns resultados obtidos na roda de conversa com os jovens. 
O estudo de Sales, Heijmans e Silva (2017) realizado por meio de survey com 1.570 ex-alunos que concluíram ou abandonaram cursos técnicos entre 2006 e 2010 em instituições da rede federal mineira, com o objetivo de encontrar relações entre variáveis para explicar o acesso dos(as) jovens egressos da educação técnica ao ensino superior. O estudo constatou que a transição educacional do ensino técnico de nível médio para o ensino superior ocorreu de forma positiva para 61,7\% dos participantes da pesquisa, com maior probabilidade entre os indivíduos com maior renda e com pais com maior grau de escolaridade. Além disso, a análise aponta para uma maior inserção no ensino superior entre indivíduos no qual o ensino médio foi realizado de forma integrada. Assim sendo, trata-se de uma fração do ensino público que possui maior tendência à efetivação das expectativas de ingressar no ensino superior.

Nesse sentido, os(as) jovens questionados na pesquisa predominantemente desejam ingressar no ensino superior após o fim do ensino médio (70,7\%). Ao investigar as áreas do conhecimento que esses(as) jovens pretendem ingressar após a conclusão do ensino médio integrado, verificamos que a indecisão marca a maior parte dos projetos dos(as) jovens em relação ao ingresso no ensino superior (41,5\%). O curso de engenharia - em suas diferentes ramificações - se sobrepõe como principal opção dos estudantes que denominaram as escolhas, correspondendo a aproximadamente 1 em cada 4 respostas $(27,4 \%)$.

Ao relacionarmos as variáveis de sexo a escolha dos cursos, identificamos diferenças. Os cursos mencionados pelos alunos do sexo masculino foram: engenharia (41,3\%), indecisos (39,7\%), ciência da computação (10\%), automação industrial $(2,5 \%)$, arquitetura $(1,3 \%)$, cinema $(1,3 \%)$, economia $(1,3 \%)$, gastronomia $(1,3 \%)$, redes de computadores $(1,3 \%)$.

Entre as alunas, os cursos de nível superior assinalados foram: indecisos (57,9\%), medicina $(9,6 \%)$, engenharia $(7,7 \%)$, psicologia $(5,8 \%)$, arquitetura $(3,8 \%)$, artes cênicas $(1,9 \%)$, biologia $(1,9 \%)$, veterinária $(1,9 \%)$, enfermagem $(1,9 \%)$, pedagogia $(1,9 \%)$, letras $(1,9 \%)$, ciências sociais $(1,9 \%)$, odontologia $(1,9 \%)$, design gráfico $(1,9 \%)$.

Ao realizar uma comparação entre as expectativas de futuro de moças e rapazes, observamos maior variedade de profissões na descrição das escolhas dos cursos de educação superior das moças, como também, a tendência de jovens do sexo feminino estarem mais propensas a ingressar no ensino superior em áreas como saúde e educação (GRAF; DIOGO, 2009).

A maior parte dos cursos está voltada à formação de bacharéis, constituindo $91,1 \%$ dos respondentes, em relação a 8,2\% que apontaram disciplinas da escola básica e 0,7\% ao curso de pedagogia. Verificamos que a maior parte das respondentes desse grupo, cuja formação propicia o exercício da docência via licenciatura são do sexo feminino. Estes dados acima corroboram com os dados obtidos em estudo com jovens de escolas públicas e privadas do 3 ano do ensino médio sobre a procura pela carreira docente no Brasil (TARTUCE; NUNES; ALMEIDA, 2010).

Ainda que o público feminino opte por profissões diversas, quando comparamos com as escolhas do público masculino, percebemos que a divisão sexual do trabalho se faz presente nas escolhas desses(as) estudantes. Essa divisão sexual do trabalho condiciona a própria constituição das identidades do masculino e do feminino, atribuindo responsabilidades e tarefas diferenciadas para homens e mulheres. É importante ressaltar, conforme afirma Cabral (2005, p. 11), "Não quer dizer que uma carreira seja mais masculina ou feminina que outra, mas que os valores que as construíram têm imbricados a história e a cultura de homens e mulheres".

\section{Considerações finais}

Foi possível perceber com o estudo que dentro de uma escola de educação tecnológica, há relações generificadas no que concerne à experiência de cursar o ensino médio integrado e as expectativas de inserção profissional dos(as) jovens. Nesse sentido, apontamos para a baixa quantidade de professoras que compõem o quadro docente das disciplinas profissionalizantes e as desigualdades no uso das ferramentas nos laboratórios. 
A baixa quantidade de professoras que compõem o quadro docente das disciplinas profissionalizantes também é um elemento de destaque para a compreensão das diferenças e desigualdades de gênero que compõem um curso técnico. Argumentamos com a hipótese de que essa predominância de professores pode dificultar a identificação das alunas de cursos voltados às áreas tecnológicas. Logo, a continuidade das estudantes em áreas voltadas a tecnologia e as ciências da computação envolve, também, a inserção de professoras no quadro docente responsável pelas disciplinas do itinerário profissionalizante.

As desigualdades no uso das ferramentas no laboratório não são percebidas pela maior parte dos(as) estudantes da escola. A pesquisa também apontou que nos espaços onde possui menos máquinas e onde o trabalho precisa ser mais dividido entre os participantes, essas desigualdades ficam mais evidentes. Portanto, infraestrutura da escola é um fator que precisa ser considerado no momento de formulação das políticas, a fim de evitar a produção de mais desigualdades e o afastamento das mulheres de carreiras tecnológicas.

Conforme foi possível observar nos dados referentes às preferências entre itinerários formativos e da base comum, alunos e alunas atribuem diferentes significados à formação profissional. Assim, as políticas de educação profissionalizante no nível médio, precisam levar em consideração essas desigualdades efetivadas no cotidiano e as diferentes percepções dos(as) jovens.

\section{Referências}

ANJOS, Helen Vivian Moreira dos. A opção pelo ensino médio integrado: o caso dos Alunos do Instituto Federal de Educação, Ciência e Tecnologia Norte de Minas Gerais - Campus Salinas. 2013. Dissertação (Mestrado em Educação) - Programa de Mestrado em Educação Profissional, Universidade nacional de Brasília, Brasília, DF, 2013.

ARTES, Amélia Cristina Abreu; CARVALHO, Marília Pinto de. O trabalho como fator determinante da defasagem escolar dos meninos no Brasil: mito ou realidade? Cadernos Pagu, Campinas, n. 34, p. 41-74, jan./jun. 2010.

BRASIL. Ministério da Educação. Projeto político pedagógico curso de ensino médio integrado ao ensino técnico em informática. Salto: IFSP, 2017a. Disponível em: http://slt.ifsp.edu.br/portal/images/pdf/slt_ppc_tecnico_em_informtica_integrado_ao_em.pdf. Acesso em: 18 ago. 2018.

BRASIL. Ministério da Educação. Projeto político pedagógico curso de ensino médio integrado ao ensino técnico em automação industrial. Salto: IFSP, 2017b. Disponível em: http://slt.ifsp.edu.br/portal/images/pdf/slt__ppc_tecnico_ em_automacao_industrial_integrado_ao_em.pdf. Acesso em: 18 ago. 2018.

BRASIL. Ministério da Educação. Censo escolar 2017. Brasília, DF: Instituto Nacional de Estudos e Pesquisas Educacionais Anísio Teixeira, 2018.

BRASIL. Lei no 12.711. Dispõe sobre o ingresso nas universidades federais e nas instituições federais de ensino técnico de nível médio e dá outras providências. Brasília, DF: Presidência da República, 2012. Disponível em: http://www. planalto.gov.br/ccivil_03/_ato2011-2014/2012/Lei/L12711.htm. Acesso em: 4 nov. 2018.

BRASIL. Relação Candidato por vaga: Edital 674/2019. São Paulo: IFSP Campus Salto, 2019. Disponível em: https:// www.ifsp.edu.br/images/pdf/ProcessoSeletivo1sem2020/Concorrncia_Edital_674_2019.pdf. Acesso em: 18 set. 2020.

CABRAL, Carla Giovana. As mulheres nas escolas de engenharia brasileiras: história, educação e futuro. Cadernos de gênero e tecnologia, Curitiba, v. 1, n. 4, p. 9-19, 2005.

CÂNDIDO, Antônio. A estrutura da escola. In: PEREIRA, Luiz; FORACHI, Marialice M. Educação e sociedade (Leituras de sociologia da educação). 9. ed. São Paulo: Companhia Editora Nacional, 1978. p. 107-128.

CARVALHO, Marília Gomes de; TORTATO, Cíntia de Souza Batista. Gênero: considerações sobre o conceito. In: LUZ, Nancy Stancki da; CARVALHO, Marília Gomes de; CASAGRANDE, Lindamir Salete (org.). Construindo a igualdade na diversidade: gênero e sexualidade na escola. Curitiba: UTFPR, 2009. p. 21-32.

CAÚ, José Nildo Alves. A juventude do curso técnico integrado em agropecuária do IFPE: desejos, expectativas e experiências vivenciadas para construção do seu projeto de vida. 2017. Tese (Doutorado em Educação) - Programa de Pós-Graduação em Educação, Universidade Federal de Pernambuco, Pernambuco, 2017.

CONNELL, Raewyn. Gênero em termos reais. São Paulo: nVersos, 2015.

CONNELL, Raewyn; PEARSE, Rebecca. Gênero: uma perspectiva global. São Paulo: nVersos, 2016.

FAULKNER, Wendy. Tornar-se e pertencer: processos de generificação na engenharia. Cadernos de gênero e tecnologia, Curitiba, v. 3, n. 10, p. 21-32, abr./jun. 2007. 
FERREIRA, Sandra Lúcia; ANDRADE, Andrea de; SOUZA, Fernanda Evelin Camarço de. Reflexões sobre a expansão dos Institutos Federais no Estado de São Paulo. Jornal de políticas educacionais, Curitiba, v. 12, n. 2, p. 1-19, jan. 2018. FERRETI, Celso João; SILVA, Monica Ribeiro da. Reforma do ensino médio no contexto da medida provisória no 746/2016: estado, currículo e disputas por hegemonia. Educação e Sociedade [on-line], Campinas, v. 38, n. 139, p. 385-404, abr./jun. 2017.

FREITAS, Henrique; OLIVEIRA, Mírian; SACCOL, Amarolinda Zanela; MOSCAROLA, Jean. O método de pesquisa survey. Revista de administração, São Paulo, v. 35, n. 3, p. 105-112, jul./set. 2000.

FUNDAÇÃO SEADE. Informações dos municípios paulistas. São Paulo: Seade, 2019. Disponível em: http://www.imp. seade.gov.br/frontend/\#/. Acesso em: 5 nov. 2019.

GRAF, Laila Priscila; DIOGO, Maria Fernanda. Projeções juvenis: visões ocupacionais e marcas de gênero. Revista brasileira orientação profissional, São Paulo, v. 10, n. 1, p. 71-82, jun. 2009.

INSTITUTO BRASILEIRO DE GEOGRAFIA E ESTATÍSTICA (IBGE). Cidades e Estados. Rio de Janeiro: IBGE, 2019a. Disponível em: https://www.ibge.gov.br/cidades-e-estados.html. Acesso em: 5 nov. 2019.

INSTITUTO BRASILEIRO DE GEOGRAFIA E ESTATÍSTICA (IBGE). Educação: Pesquisa Nacional por Amostra de Domicílios 2018. Rio de Janeiro: IBGE, 2019b.

INCERTI, Tânia Gracieli Veja; CARVALHO, Ana Maria de; CASAGRANDE, Lindamir Salete. As mulheres docentes do IFPR e a questão de gênero: protagonistas ou coadjuvantes no processo formativo dos cursos técnicos? Cadernos de gênero e tecnologia, Curitiba, v. 10, n. 35, p. 40-57, jan./jun. 2017.

KRAWCZYK, Nora. Reflexão sobre alguns desafios do ensino médio no Brasil hoje. Cadernos de pesquisa, São Paulo, v. 41, n. 144, p. 752-769, set./dez. 2011.

LEÃO, Geraldo. O que os jovens podem esperar da reforma do ensino médio brasileiro. Educação em Revista, Belo Horizonte, n. 34, 2018.

LEVI, Giovanni; SCHMITT, Jean-Claude. História dos jovens. São Paulo: Companhia das Letras, 1996.

MOTTA, Vânia Cardoso da; FRIGOTTO, Gaudêncio. Por que a urgência da reforma do ensino médio? medida provisória no 746/2016 (Lei no 13.415/2017). Educação e Sociedade, Campinas, v. 38, n. 139, p. 355-372, abr./jun. 2017. PARANHOS, Runolfo; FIGUEIREDO FILHO, Dalson Britto; ROCHA, Enivaldo Carvalho da; SILVA JUNIOR, José Alexandre da. Corra que o survey vem aí. Noções básicas para cientistas sociais. Revista Latinoamericana de metodologia de la investigación social, Argentina, ano 3, n. 6, mar. 2013.

PERALVA, Angelina T. O jovem como modelo cultural. Revista Brasileira de Educação, Rio de Janeiro, n. 5, maio/ ago. 1997; n. 6, set./dez. 1997.

RAMOS NETO, João Oliveira. Como a reforma do Ensino Médio afeta a rede federal de Educação Tecnológica. Multi-ScienceJournal, Urutaí, v. 1, n. 7, p. 9-11, set./nov. 2017.

SALES, Paula Elizabeth Nogueira; HEIJMANS, Rosemary Dore; SILVA, Carlos Eduardo Guerra. Análise multinível da transição estudantil do curso técnico para o ensino superior. Estudos em Avaliação Educacional, São Paulo, v. 28, n. 69, p. 896-925, set./dez. 2017.

SANTOS, Danielle de Souza. Democratização do acesso ao ensino médio no IFSP: o contexto de implementação da lei de reserva de vagas. 2018. Tese (Doutorado em Educação) - Programa de Pós-Graduação em Educação, Universidade Estadual de Campinas, Campinas, 2018.

SANTOS, Solange Ferreira dos; FARIAS, Benedito Guilherme Falcão. Gênero, educação e artefatos tecnológicos: os diferentes meios para ensinar. In: LUZ, Nancy Stancki da; CARVALHO, Marília Gomes de; CASAGRANDE, Lindamir Salete (org.). Construindo igualdade na diversidade: gênero e sexualidade na escola. Curitiba: UTFPR, 2009. p. 91-108. SCOTT, Joan. Gênero: uma categoria útil de análise histórica. Educação \& Realidade, Porto Alegre, v. 20, n. 2, p. 71-79, jul./dez. 1995.

SPOSITO, Marília Pontes; SOUZA, Raquel de; SILVA, Fernanda Arantes e. A pesquisa sobre jovens no Brasil: traçando novos desafios a partir de dados quantitativos. Educação e Pesquisa, São Paulo, v. 44, e170308, 2018.

SPOSITO, Marilia Pontes; TARÁBOLA, Felipe de Souza. Qualitative Methodologies and the Life Course in Brazil. In: GEORGE Noblit (org.). Oxford Research Encyclopedia of Education. 1. ed. EUA: Oxford University Press USA, 2019. v. I. p. 1-25. Disponível em: https://oxfordre.com/education/view/10.1093/acrefore/9780190264093.001.0001/acrefore-9780190264093-e-357. Acesso em: 5 maio 2020.

TARTUCE, Gisela Lobo Baptista Pereira; NUNES, Marina Muniz Rossa; ALMEIDA, Patrícia Cristina Albieri de. Alunos do ensino médio e atratividade da carreira docente no Brasil. Cadernos de Pesquisa, São Paulo, v. 40, n. 140, p. 445-477, maio/ago. 2010.

WELZER-LANG, Daniel. Os homens e o masculino numa perspectiva de relações sociais de sexo. In: SCHPUN, Mônica Raíssa (org.) Masculinidades. São Paulo: Boitempo; Santa Cruz do Sul: Edunisc, 2004. p. 107-128. 